\title{
La impunidad en el contexto de la desaparición forzada en México Impunity in the context of enforced disappearance in Mexico
}

\author{
José Antonio Guevara Bermúdez \\ Comisión Mexicana de Defensa y Promoción de los Derechos Humanos \\ ja_guevara1@me.com \\ Lucía Guadalupe Chávez Vargas \\ Comisión Mexicana de Defensa y Promoción de los Derechos Humanos \\ lucygchavezv@gmail.com
}

Recibido / received: 14/01/2018

Aceptado / accepted: 10/03/2018

DOI: https://doi.org/10.20318/eunomia.2018.4161

\begin{abstract}
Resumen
La impunidad se define como la ausencia de castigo a los responsables de cometer delitos. En el caso de México, destaca la impunidad por el crimen de desaparición forzada de personas. La desaparición forzada se ha manifestado en México al menos en tres periodos: la Guerra Sucia, el conflicto Zapatista y la guerra contra las drogas. Los crímenes que se han cometido en esos contextos permanecen sin castigo, por lo que las víctimas permanecen sin ser reparadas de manera integral.

El artículo busca dimensionar el caso mexicano sobre el crimen de la desaparición forzada a la luz de los elementos que componen el concepto de impunidad. Además, plantea una serie de propuestas tendientes a contribuir a la erradicación de la impunidad por graves violaciones a derechos humanos.
\end{abstract}

\section{Palabras clave}

Derechos Humanos, impunidad, desaparición forzada, crimen, violencia.

\begin{abstract}
Impunity is defined as the absence of punishment for those responsible for committing crimes. In the case of Mexico, impunity stands out for the crime of enforced disappearance of persons. The enforced disappearance has manifested in Mexico in at least three periods: the Dirty War, the Zapatista conflict and the war on drugs. The crimes that have been committed in those contexts remain unpunished, so that the victims remain without an integral reparation.

The article seeks to analyze the Mexican case on the crime of forced disappearance considering the elements that make up the concept of impunity. In addition, it explores a series of proposals tending to contribute to the eradication of impunity for serious human rights violations.
\end{abstract}

\section{Keywords}

Human Rights, impunity, forced disappearance, crime, violence. 
SUMARIO. 1. Introducción. 2. Contexto y cifras sobre la impunidad en las desapariciones de ayer y hoy. 3. La manifestación de la impunidad en el caso mexicano. 3.1 Propuestas para erradicar la impunidad en casos de desaparición. 4. Conclusiones.

\section{Introducción}

La desaparición forzada de personas es considerada una de las más graves violaciones a los Derechos Humanos. Vulnera, de formas inexplicables, no sólo a las víctimas y su entorno familiar y social inmediato, sino a toda la humanidad en su conjunto, ya que la desaparición crea una incertidumbre aterrorizante y casi permanente sobre el paradero o suerte de las víctimas.

Este crimen ha sido definido por la Convención Internacional para la Protección de todas las Personas contra las Desapariciones Forzadas como:

[E]l arresto, la detención, el secuestro o cualquier otra forma de privación de libertad que sean obra de agentes del Estado o por personas o grupos de personas que actúan con la autorización, el apoyo o la aquiescencia del Estado, seguida de la negativa de reconocer dicha privación de libertad o del ocultamiento de la suerte o el paradero de la persona desaparecida, sustrayéndola a la protección de la ley (ONU, 2006).

La desaparición forzada no es un fenómeno nuevo en México, se practicó con gran intensidad por autoridades estatales en el periodo conocido como "Guerra Sucia" durante los años sesenta, setenta y ochenta; seguido del conflicto Zapatista en los noventa y, más recientemente, desde que inició la guerra contra las drogas en diciembre de 2006.

Más allá de vivir con la incertidumbre de no saber el paradero de la persona desaparecida, los familiares de las víctimas tienen que enfrentarse a una total impunidad e inacción de las autoridades y aparatos de justicia, ya que el gobierno de México ha sido renuente a aceptar la existencia de esta crisis humanitaria, la cual claramente tiene un carácter sistemático y generalizado.

Derivado del contexto de desaparición forzada en México, se publicó la Ley General en Materia de Desaparición Forzada de Personas, Desaparición Cometida por Particulares y del Sistema Nacional de Búsqueda de Personas (2017). Esta Ley obedece a las exigencias de víctimas, organizaciones y colectivos de la sociedad civil, así como a recomendaciones de mecanismos internacionales de supervisión de los Derechos Humanos y a la sentencia de la Corte Interamericana de Derechos Humanos sobre el Caso Radilla Pacheco contra México (Corte Interamericana de Derechos Humanos, 2009).

No obstante, en la Ley no se contempló una adecuada clasificación de la desaparición forzada, confundiéndose una persona desaparecida con una extraviada. Igualmente, ya en la práctica, las autoridades equiparan la desaparición a un "secuestro". Asimismo, nos encontramos con la falta de voluntad y capacidad del Gobierno mexicano, particularmente de aquellas autoridades encargadas de impartir justicia para investigar, procesar y sancionar delitos comunes y particularmente crímenes graves como la desaparición forzada de personas. Por todo ello, hablamos de una grave crisis de impunidad en el país. 


\section{Contexto y cifras sobre la impunidad en las desapariciones de ayer y hoy}

Como ya se ha mencionado, en México hemos vivido al menos tres periodos de violencia en donde el Estado ha recurrido a la desaparición forzada de personas. Al primero, se le conoce como "Guerra Sucia" y fue un periodo de conflicto armado comprendido entre los años sesenta y principios de los ochenta. Lo que generó ese conflicto, cuyo punto más álgido se encontró en el Estado de Guerrero y, en particular, en el municipio de Atoyac, fue la contradicción entre la posesión de la tierra, el control sobre los productos de la tierra y los mecanismos para quedarse con los beneficios de la producción, posteriores al reparto agrario y las esperanzas que ello generó en la fuerza trabajadora campesina posterior a la Revolución Mexicana. Cuando las organizaciones sociales optaron por el empoderamiento político para la exigencia y consecución de sus derechos, los gobernantes descalificaron toda propuesta de cambio social (FEMOSPP, 2006: 5).

En el informe de la FEMOSPP (2006), Fiscalía creada con el propósito de investigar penalmente estos hechos, se concluyó que el Estado mexicano cometió crímenes graves en contra de la población civil, por lo que a los movimientos sociales sólo les quedó la vía de la rebelión.

"[El Estado] calificó y persiguió la lucha democrática como acto subversivo. Quienes buscaban un cambio por vías legales - de la gestión, de la participación democrática y del liderazgo social- fueron señalados como subversivos y agitadores, como guerrilleros, fueron perseguidos muertos, desaparecidos o encarcelados, particularmente por cuerpos de seguridad pública, en especial por el Ejército mexicano" (FEMOSPP, 2006: 7).

Se ha documentado que el Ejecutivo Federal solicitó el apoyo del Ejército de manera oficial, motivando la solicitud en la subversión y la supuesta comisión de actos delictivos del Partido de los Pobres, que según las autoridades estaba ideológica, política y militarmente preparado. Así, se dijo que era necesario utilizar "fuerzas de golpeo que en forma clandestina actúan directamente en contra de los miembros ya identificados y ubicados, para quebrantarlos moral y materialmente, hasta lograr su total destrucción. Se requiere, para lograr lo anterior, el apoyo material y moral, por parte de las autoridades en todos los niveles." (Corte Interamericana de Derechos Humanos, 2009: 151 y ss.). Lo anterior, no contaba con ningún sustento jurídico y no se acreditaba tampoco una situación de urgencia y gravedad que amenazara la seguridad del Estado.

En total, la FEMOSPP (2006) logró documentar en su informe los casos de 788 personas detenidas desaparecidas en ese periodo. Hasta el momento, solo tenemos noticia de una sentencia por hechos de desaparición forzada ocurridos en el estado de Sinaloa en contra de una sola persona (Causa Penal 179/2006, 2009).

El segundo periodo al que nos referimos es el año de 1994, cuando estalló una lucha armada entre el Ejército Zapatista de Liberación Nacional (EZLN) y el Ejército mexicano, marco en el cual se cometieron graves violaciones a los Derechos Humanos por ese último. El caso Ejido Morelia, documentado por la Comisión Mexicana de Defensa y Promoción de los Derechos Humanos $(\mathrm{CMDPDH})^{1}$, ejemplifica la práctica de abusos militares en el periodo de la lucha de

\footnotetext{
${ }^{1}$ La Comisión Mexicana de Defensa y Promoción de los Derechos Humanos es una organización de la sociedad civil que acompaña de manera integral a víctimas de violaciones graves a derechos humanos y contribuye a la erradicación de las causas que las producen, por medio del diseño y ejecución de
} 
las Fuerzas Armadas Mexicanas contra el EZLN y muestra la práctica de la tortura, seguida de la ejecución arbitraria y la desaparición forzada a manos de militares, en contra de simpatizantes del movimiento Zapatista $(\mathrm{CIDH}, 1998)^{2}$.

Los hechos del caso "Ejido Morelia" no han sido sancionados, a 22 años de ocurridos permanecen en la impunidad. A la par, permanecen sin sanción decenas de casos de violaciones de los Derechos Humanos ocurridas en ese contexto.

La falta de sanción de los crímenes graves como la desaparición forzada ha tenido como consecuencia su repetición; por ejemplo, en el contexto actual en México. El 10 de diciembre de 2006, apenas unos días después de que llegara a la presidencia, Felipe Calderón Hinojosa hizo una declaración pública de guerra contra las drogas ${ }^{3}$. La estrategia de esa guerra implicó una estrategia de seguridad pública consistente en la confrontación violenta en contra de los cárteles del narcotráfico a través de operativos conjuntos en donde participaban activamente las Fuerzas Armadas Mexicanas.

A once años de la estrategia de seguridad, los datos que documentan crímenes graves, entre ellas la desaparición forzada de personas, son simplemente aterradores.

El Registro Nacional de Personas Extraviadas o Desaparecidas, registro oficial de las autoridades mexicanas, hasta el 1 de enero de 2018 reporta 34.656 personas desaparecidas, cifra que desde 2011 ha ido en aumento tal y como se muestra en la Figura 1 (Secretariado Ejecutivo del Sistema Nacional de Seguridad Pública, 2018).

Figura 1

Personas extraviadas y desaparecidas en México

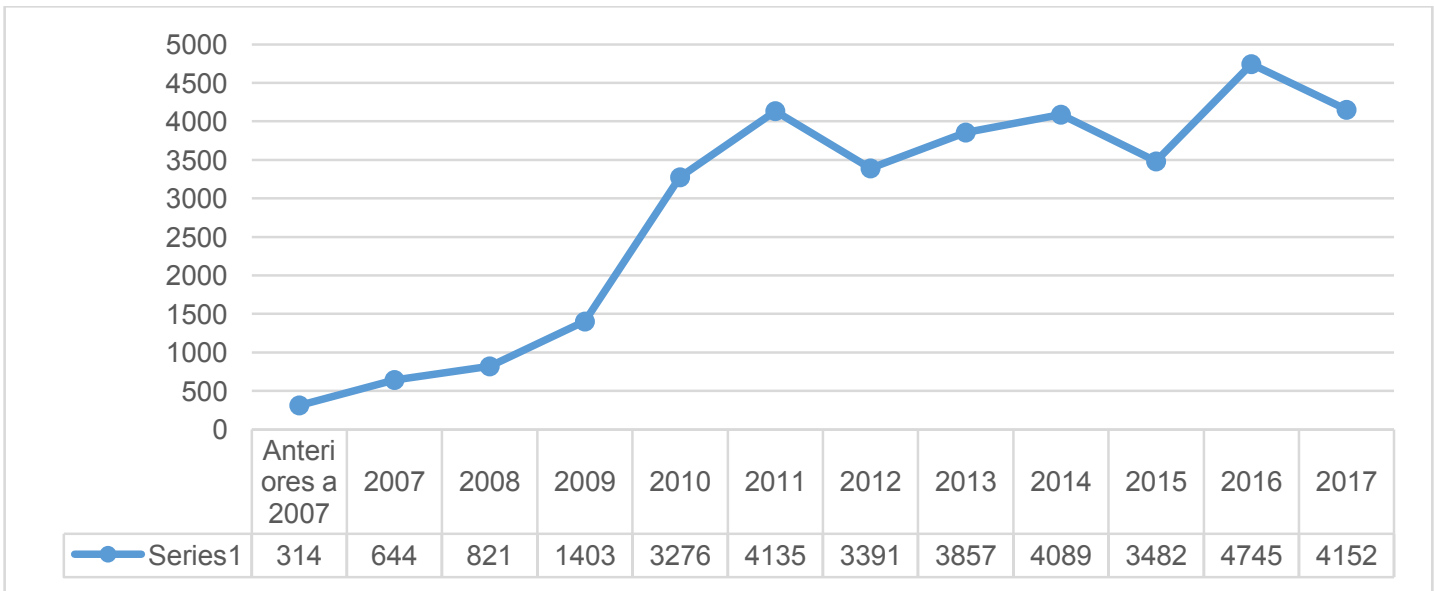

Fuente: Secretariado Ejecutivo del Sistema Nacional de Seguridad Pública.

estrategias legales, psicosociales, de investigación, incidencia y difusión, para construir una sociedad justa e igualitaria. El autor y la autora de este artículo forman parte de la organización.

2 Los hechos del caso Ejido Morelia se refieren a la detención, tortura, desaparición y posterior ejecución arbitraria de los señores Severiano Santiz Gómez, Hermelindo Santiz Gómez, y Sebastián Santiz López el día 7 de enero de 1994 por agentes del ejército mexicano (CIDH, 1998).

${ }^{3}$ Los términos "guerra" y "batalla frontal" fueron empleados por el entonces presidente Felipe Calderón para referirse a acciones de "ofensiva" de combate a la delincuencia, el crimen organizado y el narcotráfico, que requerían un despliegue numeroso de elementos militares. (Astorga, 2015). 
De acuerdo con la Procuraduría General de la República $(P G R)^{4}$ que es el órgano encargado de la persecución de los delitos en México, se reportaron un total de 732 averiguaciones previas (investigaciones) iniciadas en el fuero federal por el delito de desaparición forzada de 2006 a marzo de 2017, de las cuales la PGR solamente judicializó 19. En total, el Poder Judicial emitió, en ese mismo periodo, 9 sentencias condenatorias sobre desaparición forzada, solo 7 de ellas por expedientes iniciados después del 2006 (CJF, 2017), cifra que evidentemente no corresponde con la magnitud del fenómeno de la desaparición.

A este dato se le debe sumar que las Fiscalías Estatales informaron sobre un total de 1.197 denuncias por el crimen de desaparición forzada en el periodo mencionado.

En el ámbito de los mecanismos cuasi jurisdiccionales, la Oficina del Ombudsman Nacional, reportó 333 quejas interpuestas en este organismo por desaparición forzada de 2007 a octubre de 2017 (CNDH, 2017) y se reportaron 1.050 quejas interpuestas en las Oficinas Estatales del Ombudsman por esa violación a los Derechos Humanos ${ }^{5}$.

De acuerdo con un análisis de la CMDPDH de 204 documentos emitidos por la $\mathrm{CNDH}^{6}$, en los que comprueba que se cometieron graves violaciones de los Derechos Humanos, tenemos como resultado que en 60 se hace referencia a desapariciones forzadas cometidas en el contexto de la estrategia de seguridad denominada "guerra contra las drogas". En esas recomendaciones se reconocen a 239 víctimas de desaparición forzada.

Como responsables de ese crimen se identificaron a las Fuerzas Armadas Mexicanas y a las Policías Federal, Estatal y Municipal, pero también al crimen organizado ${ }^{7}$.

La sistematización que realizamos en nuestra base de datos nos deja ver la última ubicación de las víctimas en los episodios de desaparición, que se desagregan de la siguiente manera:

Tabla 1

Tipos de ubicaciones en casos de desaparición forzada

\begin{tabular}{ll}
\hline Tipo de ubicación & Suma \\
\hline Cuarteles militares & 13 \\
Bases o campamentos militares & 5 \\
Hogar de la víctima & 8 \\
Calle o carretera & 12
\end{tabular}

Hoteles, restaurantes o establecimientos 2

similares

Parque, parque infantil, campo de juego 2

Elaboración propia. Fuente: Base de datos sobre recomendaciones de la CMDPDH

\footnotetext{
${ }_{5}^{4}$ La PGR en México es institución encargada de conducir las investigaciones penales.

5 Datos obtenidos a partir de solicitudes de información pública realizadas a los Estados de la República.

${ }^{6}$ Los documentos emitidos por la CNDH son conocidos como recomendaciones. El análisis que se realizó abarca desde diciembre de 2006 a junio de 2017. Se analizaron 204 recomendaciones emitidas por la $\mathrm{CNDH}$ que tienen que ver con violaciones graves a los Derechos Humanos: tortura, desaparición, ejecución y detención arbitraria.

${ }^{7}$ En un episodio de desaparición pueden estar involucradas autoridades de distintas unidades de la Administración Pública.
} 
La autoridad con mayor número de quejas y recomendaciones, así como de víctimas acumuladas por desaparición forzada son las Fuerzas Armadas, particularmente, la Secretaría de la Defensa Nacional. A pesar de que la participación de militares en desapariciones forzadas ha sido probada, no se ha sancionado a la mayoría de los responsables directos de cometer esas violaciones y tampoco se han investigado siquiera a altos mandos que pudieron estar implicados en la comisión de esos crímenes.

Además de las cifras que hemos podido recolectar a nivel nacional, contamos con datos y declaraciones de mecanismos internacionales que refieren la magnitud de las desapariciones en el país. Verbigracia, en el periodo que trascurre desde 2012 al 26 de octubre de 2017, sumaban 417 las acciones urgentes con relación a las cuales el Comité contra la Desaparición Forzada había requerido a algún Estado para adoptar todas las medidas necesarias, incluidas medias cautelares, para ubicar personas desaparecidas y protegerlas; 305 de esos casos eran sobre México (Comité contra la Desaparición Forzada, 2017).

El Alto Comisionado de la Organización de las Naciones Unidas para los Derechos Humanos, Zeid Ra'ad Al Hussein (2015), reconoció que desde 2007 había "al menos 26,000 personas cuyo paradero se desconoce" y cuyas ejecuciones en muchos casos "presuntamente han sido llevadas a cabo por autoridades federales, estatales y municipales, incluyendo la Policía y algunas partes del Ejército, ya sea actuando por sus propios intereses o en colusión con grupos del crimen organizado". Además, señaló que "para ser un país que no se encuentra en medio de un conflicto, las cifras calculadas son, simplemente, impactantes".

En el ámbito regional, la Comisión Interamericana de Derechos Humanos $(\mathrm{CIDH}, 2015)$ en su informe sobre la situación de los Derechos Humanos, derivado de su visita in loco a México, describió un clima de violencia generalizada en el país. Afirmó la generalidad con la que se perpetran la tortura, la desaparición forzada y la impunidad (CIDH, 2016: 13 y ss., 48 y ss. y 67 y ss.). La CIDH "pudo constatar que la desaparición de personas en grandes extensiones del territorio mexicano ha alcanzado niveles críticos" (ibídem: 100). Refirió también que "[l]as cifras oficiales proporcionadas, junto con la información recibida de diversas regiones del país, evidencian que las desapariciones son generalizadas en México" (ibíd: 106 y ss.). Manifestó su preocupación por la falta de disponibilidad de datos a pesar de la magnitud de la problemática ya que "[l]a información disponible no especifica los casos en los que podría haber indicios de desaparición forzada, extravíos u otros tipos de ausencia" (ibíd: 107 y ss.).

Es así, que el contexto de violencia en el país plantea serios retos para la consecución de la justicia, verdad y reparación de las víctimas de la desaparición en el país, tanto por los hechos cometidos en el pasado como por los que ocurren en la actualidad en el contexto de la guerra contra las drogas.

\section{La manifestación de la impunidad en el caso mexicano}

Si definimos la impunidad y subsumimos sus elementos en un contexto concreto, en este caso el mexicano, podemos ver con claridad su relación con la violencia y con las violaciones graves de los Derechos Humanos, por ejemplo, con la desaparición de personas. 
El concepto de impunidad para efectos de este texto lo limitaremos al ámbito jurídico ${ }^{8}$. Desde la disciplina jurídica, tenemos que el concepto de impunidad se ha definido en varios instrumentos normativos de carácter internacional y en sentencias.

Las Organización de las Naciones Unidas (ONU, 2005), en el Conjunto de principios actualizado para la protección y la promoción de los Derechos Humanos mediante la lucha contra la impunidad, define a ésta como:

[L]a inexistencia, de hecho o de derecho, de responsabilidad penal por parte de los autores de violaciones, así como de responsabilidad civil, administrativa o disciplinaria, porque escapan a toda investigación con miras a su inculpación, detención, procesamiento y, en caso de ser reconocidos culpables, condena a penas apropiadas, incluso a la indemnización del daño causado a sus víctimas.

Ese Conjunto de principios, igualmente señala que la impunidad:

[C]onstituye una infracción de las obligaciones que tienen los Estados de investigar las violaciones, adoptar medidas apropiadas respecto de sus autores, especialmente en la esfera de la justicia, para que las personas sospechosas de responsabilidad penal sean procesadas, juzgadas y condenadas a penas apropiadas, de garantizar a las víctimas recursos eficaces y la reparación de los perjuicios sufridos de garantizar el derecho inalienable a conocer la verdad y de tomar todas las medidas necesarias para evitar la repetición de dichas violaciones (ONU, 2005).

También, en el Plan de Acción de las Naciones Unidas sobre la Seguridad de los Periodistas y la Cuestión de la Impunidad (ONU, 2012), se define a la impunidad como "[L]a incapacidad para llevar ante la justicia a los autores de violaciones de derechos humanos".

La impunidad, puede ocurrir antes, durante o después de un proceso judicial o independientemente de él. Al hablar de los Derechos Humanos, la impunidad surge cuando el autor de una violación a esos derechos, se mantiene ajeno a: i) las investigaciones encaminadas a su inculpación, detención o procesamiento; o, ii) en el caso de ser reconocido como culpable, a una pena apropiada y/o a la indemnización del daño causado (Demanda de inconstitucionalidad contra los artículos $1^{\circ}, 4^{\circ}, 6^{\circ}$ y $7^{\circ}$ todos parcialmente, de la Ley 1424 de 2010,2011 ).

De las definiciones y precisiones anteriores, siguiendo la clasificación de Kai Ambos (1999) respecto de los tipos de impunidad, podemos reconocer una impunidad de hecho y otra de derecho. A esas categorías, el autor las propone como la impunidad jurídica material y la impunidad procesal y agrega además, la idea de una impunidad estructural.

La impunidad jurídica material o de derecho se entiende cuando en el Derecho penal no se prevé la persecución penal de una conducta o bien, en el contexto de las violaciones graves de los Derechos Humanos, cuando por tratados o leyes de amnistía, generalmente en el afán de la reconciliación nacional, se establece que los presuntos responsables no serán enjuiciados y entonces se renuncia a las sanciones penales (Ambos, 1999: 35-36).

En México podemos decir que, si bien se tipifica la desaparición forzada de personas mediante la Ley General en Materia de Desaparición Forzada de

\footnotetext{
${ }^{8}$ Aunque para examinar el fenómeno completo de los efectos y causas de la impunidad se debe explicar desde una dimensión además de jurídica, política, economía y de la antropología social, por mencionar sólo algunas disciplinas.
} 
Personas, Desaparición Cometida por Particulares y del Sistema Nacional de Búsqueda de Personas (México, 2017a), como se mencionó, no se deja clara aún la diferencia entre personas desaparecidas y no localizadas. A estas últimas, la Ley las define como "la persona cuya ubicación es desconocida y que de acuerdo con la información que se reporte a la autoridad, su ausencia no se relaciona con la probable comisión de algún delito" (art. 4). Mientras que a una persona desaparecida la concibe como aquella cuya "ausencia se relaciona con la comisión de un delito" (art. 4), lo cual solamente se podría concluir mediante una investigación sobre la forma y causa de la desaparición.

La definición sobre la calidad de víctima de desaparición plantea al menos dos problemas que rompen con el espíritu de protección a las personas desaparecidas que debería tener la Ley. En primer lugar, impone la obligación a los denunciantes de la desaparición de proporcionar información relacionada con las causas que la provocaron, transmitiendo a estos, parcialmente, la carga de la prueba. En segundo lugar, dificulta un diagnóstico serio que permita dimensionar el problema de la desaparición en el país. Esa omisión legislativa puede generar subregistros de casos de personas desaparecidas y por lo tanto generar una equivocada adopción de políticas.

Igualmente, no se percibe completamente clara la disposición que regula la responsabilidad del superior jerárquico, la cual no corresponde con el Derecho penal internacional, ya que no amplía la responsabilidad a casos en donde los altos mandos debían ejercer un control apropiado sobre sus subordinados para prevenir, reprimir o denunciar la desaparición (Estatuto de Roma de la Corte Penal Internacional, 1998: art. 28). Ello se torna sumamente importante en el contexto nacional, en donde las instituciones encargadas de la seguridad pública de todos los niveles, tienen señalamientos por cometer desaparición forzada.

Ahora bien, en cuanto a la impunidad de hecho, también llamada impunidad procesal o fáctica, se asimila a los mecanismos que impiden la sanción a los responsables, ya sea por: i) falta de denuncia, ii) falta de investigación, iii) por congestión, iv) o bien puede ser legal, esta se refiere a las normas que da alguna manera bloquean la sanción penal y v) la impunidad delictuosa, que se puede definir como medidas ilegales que afectan a las partes procesales (Ambos, 1999: 39).

Como se desprende de las cifras que expusimos, e igualmente de la experiencia en la documentación y litigio de $\operatorname{casos}^{9}$, en México, la PGR al igual que las Fiscalías Estatales no han tenido ni la voluntad ni la capacidad de investigar las miles de desapariciones que se han registrado en el país. La manera de investigar en México esos miles de casos de personas desaparecidas, continúa siendo caso por caso y no a través de análisis de contextos, redes y patrones macrocriminales.

Ese tipo de impunidad procesal, en sintonía con la ineficacia de las fiscalías está profundamente relacionado con el subregistro de delitos, es decir, los delitos que no se denuncian. En México, la cifra de delitos no denunciados oscila en el 93\%, según la Encuesta Nacional de Victimización y Percepción sobre Seguridad Pública (ENVIPE) realizada por el INEGI (2017). La ENVIPE revela que "[I]os principales motivos que llevan a la población víctima de un delito a no denunciar son circunstancias atribuibles a la autoridad, tales como considerar la denuncia como pérdida de tiempo con $33,1 \%$ y la desconfianza en la autoridad con 16,5\%" (INEGI, 2017).

\footnotetext{
${ }^{9} \mathrm{La}$ CMDPDH, organización de la que forman parte los autores, tiene bajo sus líneas de acción la defensa de víctimas de casos de violaciones graves a los Derechos Humanos.
} 
Luego, se encuentra la impunidad por congestión, que se explica por la sobrecarga laboral de la justicia penal y tiene su origen no sólo en el órgano jurisdiccional sino en las Fiscalías. Una muestra de este tipo de impunidad se representa también en la mencionada ENVIPE, en donde, del porcentaje mínimo de delitos que se denunciaron ( $9 \%$ ), en sólo el $65,2 \%$ se abrió una investigación penal. De ese número de investigaciones, el $49 \%$ de las personas encuestadas refirieron que "no pasó nada o no se resolvió la denuncia" (INEGI, 2017) y sólo el 3,5\% refirió que se reparó el daño por el delito cometido (INEGI, 2017).

Otro concepto que se propone es la impunidad legal, es decir que las normas bloquean de alguna manera la sanción legal. Ahí, tenemos normas por ejemplo en materia de facultades extra constitucionales conferidas al Ejército, como la Ley de Seguridad Interior (México, 2017b), el Código de Justicia Militar (México, 1933) y el Código Militar de Procedimientos Penales (México, 2016), que lo facultan para realizar investigaciones sobre delitos que de ninguna forma corresponden a la disciplina militar y que incluso facultan a los soldados como primer respondiente para preservar la cadena de custodia. Igualmente, les facultan a realizar acciones de seguridad pública, disfrazada de seguridad interior, y que necesariamente y sin ningún tipo de control, tienen un carácter de confidencialidad y discrecionalidad de actuación.

Finalmente, se nos propone como otro concepto la impunidad estructural, que se conceptualiza como el fruto de un contexto de violencia, desigualdad y falta de confianza por parte de los ciudadanos en la justicia como en la ausencia de funcionalidad de las instituciones estatales (Ambos, 1999: 41). En ese sentido, la ENVIPE arrojó que el $74,3 \%$ de la población percibe inseguridad en su entidad federativa. Igualmente estima a nivel nacional que "el $61,1 \%$ de la población de 18 años y más considera la inseguridad y delincuencia como el problema más importante que aqueja hoy en día en su entidad federativa, seguido del aumento de precios con $36,5 \%$ y el desempleo con $36,3 \%$ " (INEGI, 2017).

Sobre la violencia, esta se puede autoexplicar con las cifras que se presentaron en el texto relacionadas con la desaparición de personas en el marco de los tres contextos a los que nos referimos, particularmente de la estrategia de seguridad emprendida en el marco de la guerra contra las drogas.

\subsection{Propuestas para erradicar la impunidad en casos de desaparición}

En México han surgido desde la sociedad civil una serie de propuestas para contribuir a la erradicación de la impunidad por violaciones graves de los Derechos Humanos. Algunas de ellas son: un mecanismo internacional para combatir la impunidad y la corrupción, una Fiscalía autónoma y la desmilitarización de la seguridad pública.

\section{Mecanismo internacional para el combate de la corrupción y la impunidad}

El gobierno de Guatemala, en 2006, firmó un acuerdo con la ONU para establecer la Comisión Internacional contra la Impunidad en Guatemala ( $\mathrm{CICIG})$. El mandato de la $\mathrm{CICIG}$ incluye la investigación de estructuras macrocriminales, "desarticulación, en colaboración con el gobierno, de los aparatos clandestinos de seguridad y cuerpos ilegales de seguridad", así como formular "recomendaciones al Estado de Guatemala para la adopción de políticas públicas destinadas a erradicar los aparatos clandestinos y cuerpos ilegales de seguridad y prevenir su reaparición, 
incluyendo las reformas jurídicas e institucionales necesarias para este fin" (CIClG, 2018).

La persona encargada de dirigir los trabajos de la CICIG es extranjera y nombrada directamente por el Secretario General de las Naciones Unidas, de manera que, difícilmente se verá comprometida su independencia e imparcialidad.

Si bien, el mecanismo internacional ha sufrido críticas $^{10}$, lo cierto es que con sus investigaciones se ha logrado procesar y sentenciar a altos mandos responsables de actos de corrupción y de crímenes graves.

Estamos convencidos de que en México sólo será posible avanzar hacia la justicia con un mecanismo que tenga como base la cooperación internacional y que no vea comprometida su independencia con pactos de corrupción e impunidad. Además, lo vemos pertinente en virtud del rotundo fracaso de las instituciones nacionales encargadas de procurar justicia.

\section{Fiscalía General de la República autónoma}

El 29 de enero de 2016 se reformó la Constitución Política de los Estados Unidos Mexicanos para cambiar la figura de la PGR a una Fiscalía General. El corazón de la reforma fue dotar a esta nueva figura de autonomía del poder Ejecutivo, ya que la actual PGR forma parte de la Administración Pública federal y en el nombramiento de su titular interviene el presidente de la República.

Se pretende que la Fiscalía General de la República sea un organismo público autónomo que contribuya a la mejor conducción de las investigaciones penales.

El reto en este sentido es que la Fiscalía, mediante un régimen de transición adecuado, así como procedimientos claros para la investigación y persecución de los delitos, cuente con una verdadera eficacia que le permita definir un plan de persecución penal real, de acuerdo con las necesidades de seguridad y justicia en el país.

El funcionamiento de la Fiscalía, hablando del tema de las desapariciones, consideramos que deberá cambiar el paradigma de investigación caso por caso para conducir investigaciones de contexto, que ayuden a dilucidar los patrones de actuación de autoridades y crimen organizado. Sólo así se podrán generar políticas de persecución penal serias, además de modalidades de política pública para prevenir esos crímenes.

\section{Desmilitarización de la seguridad pública}

La estrategia de seguridad iniciada en 2006 trajo aparejada el uso de las Fuerzas Armadas en cuestiones de seguridad pública que corresponden a los civiles. Las Fuerzas Armadas han sido las principales señaladas cuando se cometen abusos en contra de la población civil, entre otras, han sido responsables de casos de desaparición forzada.

La garantía de la seguridad en un Estado democrático debe plantear restricciones claras en cuanto a las funciones de los militares; sin embargo, en México, como ya se mencionó, se ha decidido dotar de facultades amplias al Ejército

\footnotetext{
${ }^{10}$ Por ejemplo, los modestos resultados de los que pudo presumir la $\mathrm{CICIG}$ en sus primeros ocho años de funcionamiento, motivados en parte por la complejidad de las investigaciones.
} 
para la investigación, detención de civiles e incluso resguardo de evidencia. Actividades que, además, justificadas en un contexto de "seguridad interior" se realizan en una total opacidad ${ }^{11}$ (México, 2017b).

Es por ello que se requiere un cambio en la estrategia de seguridad de lucha contra las drogas que involucre entre otras, desmilitarizar al país.

\section{Conclusiones}

En México vivimos una crisis de violencia que, entre otros, se refleja en la magnitud del crimen de desaparición de personas. Las cifras que exponemos demuestran que desde los años sesenta es una política del Estado mexicano causar terror en distintos sectores de la población a través de la esa práctica.

Se tienen documentados numerosos casos de desaparición forzada a manos de instituciones policiacas y de las Fuerzas Armadas Mexicanas en al menos tres periodos de la historia de México: la Guerra Sucia, el conflicto Zapatista y la guerra contra las drogas. Todos estos casos se hallan impunes.

Al desmenuzar el concepto de impunidad y analizar el caso mexicano en torno a los elementos que le componen, podemos afirmar que en México se actualiza un panorama complejo en donde la impunidad ha llegado a ser estructural y tiene como consecuencia la falta de sanción de esas conductas y, por lo tanto, la repetición de crímenes graves, por ejemplo, la desaparición forzada de personas.

Ante este panorama, organizaciones de la sociedad civil, defensoras y defensores de Derechos Humanos y representantes de instituciones académicas, hemos realizado diversas propuestas que consideramos podrían contribuir a la erradicación de la impunidad:

- Un mecanismo internacional para el combate a la impunidad y la corrupción que ayude a romper con las estructuras que fomentan los pactos de impunidad en México. Asimismo, que ayude al fortalecimiento de las instituciones de justicia nacionales.

- La instalación de una Fiscalía autónoma que realice investigaciones de contexto con miras a desmantelar estructuras macrocriminales.

- La desmilitarización de la seguridad pública que modifique la estrategia de seguridad, así como la legalización de las drogas.

Esas propuestas las hemos desarrollado con base en experiencias comparadas de países de América Latina que lograron avanzar hacia la verdad, justicia y reparación de las víctimas de crímenes de Estado. Además, son cuestiones ya señaladas a través de recomendaciones por el Alto Comisionado de las Naciones Unidas para los Derechos Humanos y por Open Society Justice Initiative (2016).

\footnotetext{
${ }^{11}$ El artículo 9 de la Ley de Seguridad Interior. "La información que se genere con motivo de la aplicación de la presente Ley, será considerada de Seguridad Nacional, en los términos de las disposiciones jurídicas aplicables." Es decir, la información se clasifica como reservada al ser de Seguridad Nacional.
} 
Bibliografía

ALTO COMISIONADO DE LA ONU PARA LOS DERECHOS HUMANOS (2015). Disponible en: http://www.cinu.mx/comunicados/2015/10/declaracion-del-altocomisiona-1/.

AMBOS, K. (1999), Impunidad y derecho penal internacional, AdHoc, Argentina.

ASTORGA ALMANZA, L. (2015),

?, Grijalbo, Ciudad de México.

COMISIÓN INTERAMERICANA DE DERECHOS HUMANOS, CIDH (2015), Situación de Derechos Humanos en México. Disponible en: http://www.oas.org/es/cidh/informes/pdfs/Mexico2016-es.pdf.

COMISIÓN INTERNACIONAL CONTRA LA IMPUNIDAD EN GUATEMALA, CICIG. (2018), Mandato. Disponible en: http://www.cicig.org/index.php?page=mandato.

COMITÉ CONTRA LA DESAPARICIÓN FORZADA (2015), Observaciones finales sobre el informe presentado por México en virtud del artículo 29, párrafo 1, de la Convención (11 de febrero de 2015) CED/C/MEX/1. Disponible en: http://www.hchr.org.mx/index.php?option=com_k2\&view=item\&id=694:comitecontra-la-desaparicion-forzada-observaciones-finales-sobre-el-informepresentado-por-mexico\&ltemid=282.

COMITÉ CONTRA LA DESAPARICIÓN FORZADA (2017), Urgent actions registered by the committee.

FISCALÍA ESPECIALIZADA PARA MOVIMIENTOS SOCIALES Y POLÍTICOS DEL PASADO, FEMOSPP (2006), Informe Histórico a la Sociedad Mexicana. Disponible en: https://nsarchive2.gwu.edu//NSAEBB/NSAEBB180/index2.htm.

INSTITUTO NACIONAL DE ESTADÍSTICA Y GEOGRAFÍA, INEGI (2017), Encuesta Nacional de Victimización y Percepción sobre Seguridad Pública (ENVIPE). Disponible

en: http://www.inegi.org.mx/saladeprensa/boletines/2017/envipe/envipe2017_09.pdf.

OPEN SOCIETY JUSTICE INITIATIVE (2016), Atrocidades Innegables, OSJI, Nueva York. https://www.opensocietyfoundations.org/sites/default/files/undeniable-atrocitiesesp-20160602.pdf,

SECRETARIADO EJECUTIVO DEL SISTEMA NACIONAL DE SEGURIDAD PÚBLICA. (2018), Base de datos del Registro Nacional de Personas Extraviadas 0 Desaparecidas. Disponible en: http://www.secretariadoejecutivo.gob.mx/rnped/datos-abiertos.php.

Normativa

MÉXICO (1933), Código de Justicia Militar, Diario Oficial de La Federación, México.

MÉXICO (2016), Código Militar de Procedimientos Penales, Diario Oficial de la Federación, México.

MÉXICO (2017a), Ley General en materia de desaparición forzada de personas, desaparición cometida por particulares y del Sistema Nacional de Búsqueda de Personas, Diario Oficial de la Federación, México.

MÉXICO (2017b), Ley de Seguridad Interior, Diario Oficial de la Federación, México.

ORGANIZACIÓN DE LAS NACIONES UNIDAS, ONU (1998), Estatuto de Roma de la Corte Penal Internacional, Roma.

ORGANIZACIÓN DE LAS NACIONES UNIDAS (2005), Conjunto de principios actualizados para la protección y la promoción de los Derechos Humanos mediante la lucha contra la impunidad.

ORGANIZACIÓN DE LAS NACIONES UNIDAS, ONU (2012), Plan de acción de la ONU sobre la seguridad de los periodistas y la cuestión de la impunidad.

ORGANIZACIÓN DE LAS NACIONES UNIDAS, ONU (2017), Convención Internacional para la protección de todas las personas contra las desapariciones 
forzadas, Nueva York.

Solicitudes de acceso a la información pública

COMISIÓN NACIONAL DE LOS DERECHOS HUMANOS, CNDH. (2017). Solicitud de información folio: 3510000004217.

PROCURADURÍA GENERAL DE LA REPÚBLICA, PGR. (2017). Solicitudes de información folios: 0001700121517, 0001700018017,0001700018117 y 0001700114417.

CONSEJO DE LA JUDICATURA FEDERAL, CJF. (2017) Solicitud de información folio: 0320000161517.

$\underline{\text { Casos judiciales }}$

CAUSA PENAL 179/2006 (Juez Noveno de Distrito en el Estado de Sinaloa 2009).

COMISIÓN INTERAMERICANA DE DERECHOS HUMANOS, CIDH. (1998), Caso 11.411, Severiano y Hermelindo Santiz Gómez "Ejido Morelia", México. Disponible en: http://www.cidh.org/annualrep/97span/mexico11.411.htm

CORTE CONSTITUCIONAL DE COLOMBIA. (2011), "Demanda de inconstitucionalidad contra los artículos $1^{\circ}, 4^{\circ}, 6^{\circ}$ y $7^{\circ}$ (todos parcialmente) de la Ley 1424 de 2010, Sentencia C-771/11". En CORTE CONSTITUCIONAL DE Colombia (2011), Justicia Constitucional y Derechos Fundamentales, El control de Convencionalidad. Disponible en: http://www.kas.de/wf/doc/7426-1442-430.pdf.

CORTE INTERAMERICANA DE DERECHOS HUMANOS (2009), Caso Radilla Pacheco Vs. México. Excepciones Preliminares, Fondo, Reparaciones y Costas. Disponible en: http://www.corteidh.or.cr/docs/casos/articulos/seriec_209_esp.pdf. 